\title{
Managed Care Peer-Led Teaching: An Innovative Learning Approach Outside the College of Pharmacy Core Curriculum
}

\author{
SyHui Tang, PharmD; Julia Smith, PharmD; Wilson Lau, PharmD; Isaac Tse, PharmD, MBA; \\ Christine Tan, PharmD; Ryan Cotten, PharmD; and Amy Pittenger, PharmD, MS, PhD
}

\begin{abstract}
BACKGROUND: Managed care pharmacy is a growing field, but there are still limited educational opportunities available in pharmacy school core curricula. Students often seek self-directed learning opportunities to further explore the field.

OBJECTIVES: To (a) evaluate practicality and effectiveness of a studentdesigned managed care pharmacy elective and (b) determine emerging best practices for design and sustainability of peer-led, self-directed courses.

METHODS: A managed care elective course was designed as a student, peer-led course during the 2012-2013 school year at the University of Minnesota College of Pharmacy. As the course evolved, coordinators evaluated the effectiveness and sustainability of a student-led elective. The course required students to select a managed care topic of interest and deliver a discussion-based presentation. Teleconferencing was used to maximize participation and flexibility of pharmacist delegates from local managed care organizations who provided industry insight and expert mentorship. Data sources were gathered via course evaluation surveys, peer evaluations of presentations, and postgraduation surveys. Data were used to guide course improvement, gain insight into motivation for student participation, and evaluate the effect on career choices.
\end{abstract}

RESULTS: During the fall and spring semesters of 2014-2015, 45 students participated and completed surveys: 28 in the fall and 17 in the spring. Seventy percent of enrollees took the course because of interest in managed care; $12 \%$ took the course because of referrals from past students; and $12 \%$ enrolled to explore topics outside of the pharmacy core curriculum. After completion of the course, $50 \%$ of students felt "somewhat comfortable" in discussing managed care topics, and $31 \%$ felt "very comfortable." None of the 17 students from the spring semester class answered "not comfortable" or "somewhat not comfortable." Suggestions for improvement from the fall semester class led to smaller class size, a roundtable setting, and new meeting times. In a survey of 6 graduates, 1 student pursued a fellowship; 2 students obtained managed care residencies; and 1 student worked as a managed care pharmacist.

CONCLUSIONS: Data collected from students enrolled in the managed care elective indicated increased exposure and enhanced knowledge on topics discussed. Data also indicated value and support for the addition of peerled courses to the College of Pharmacy's curriculum. Graduates who took the course have pursued managed care careers and confirmed the benefits of peer-led learning.

J Manag Care Spec Pharm. 2017;23(7):755-59

Copyright $\odot 2017$, Academy of Managed Care Pharmacy. All rights reserved.

\section{What is already known about this subject}

A basic foundation of managed care knowledge and skills is important for general pharmacy practice.

Limited managed care content and application is provided in most pharmacy school core curricula.

Managed care is a specialized practice area requiring pharmacy expertise.

\section{What this study adds}

It is possible and effective to embed additional managed care pharmacy content and application into existing pharmacy program curricula without significant faculty burden or additional costs. Additional managed care pharmacy content and application using a student-led course design may increase the number of graduates who choose to pursue specialized training in managed care. Incorporating local managed care experts into student-led courses is an important design feature for content, application validity, and effective mentoring.

$\mathrm{M}$ anaged care pharmacy is a growing field in the health care industry, but it is still a limited component in many pharmacy school core curricula. ${ }^{1}$ Students must often seek alternative methods, such as self-directed learning opportunities, to further explore managed care pharmacy as a career option.

At the University of Minnesota College of Pharmacy (CoP), students identified a need to learn more about managed care pharmacy. In a small study conducted by Pittenger et al. (2010), they found that of the 332 pharmacy students surveyed at the CoP, $71.2 \%$ stated that they knew "none" or "a little" about how managed care pharmacy functions, yet $85.5 \%$ of them had worked in a community pharmacy, which typically crosses paths with managed care pharmacy. ${ }^{1}$ Of these students, $84.3 \%$ had determined that their knowledge regarding managed care pharmacy was "inadequate" or "very inadequate," suggesting that pharmacy schools may need to reevaluate the content of managed care pharmacy in the curriculum. ${ }^{1}$ Other schools also have recognized the need for their students to have a basic understanding of managed care pharmacy and the delivery of care to the patient population. ${ }^{2}$ 
In 2012, in response to pharmacy student interest in managed care pharmacy, the CoP's Academy of Managed Care Pharmacy (AMCP) Student Chapter Executive Board coordinated weekly lunch meetings on the Twin Cities and Duluth campuses for students to discuss managed care topics. What started as informal weekly meetings developed into an official peer-led managed care elective course (PHAR 6293), for which students could obtain elective credits after completion.

By 2015, the elective course had gathered momentum, and a more formal course agenda was developed. CoP faculty and local managed care professionals were invited to participate and enhance the overall learning experience. Students from both campuses were able to connect through video teleconference on a weekly basis to discuss managed care pharmacy topics. Topics included but were not limited to accountable care organizations, biologics and biosimilars, specialty pharmacy management, pricing, the drug approval process, utilization management, retrospective and prospective drug utilization review, pharmacy benefit management products and services, Risk Evaluation and Mitigation Strategy programs, the Affordable Care Act, the 340B Drug Pricing Program, Medicare and Medicaid, pipeline tracking, and medication therapy management. This student-led elective course has now become an integrated initiative coordinated by the CoP's AMCP chapter presidents.

\section{Purpose and Course Design}

The purpose of this initiative was to evaluate the feasibility, effectiveness, and sustainability of a student-designed and led managed care pharmacy elective. The course was designed to provide students at the $\mathrm{CoP}$ with knowledge necessary to drive the pharmacy profession forward as pharmacy shifts from the traditional fee-for-service model to a more cost-effective valuebased payment model.

Students enrolled in the course met weekly to conduct selfdirected case studies on a variety of managed care pharmacy topics through presentations and class discussions, drawing on managed care pharmacy experts from the community as quality assurance. After completion of the course, students were expected to understand the importance of managed care pharmacy in the U.S. health care system and gain experience with the application of managed care principles to authentic scenarios. The organization of the course encouraged students to explore managed care topics that interested them and to present their findings to colleagues in an informal setting, with guidance and feedback from local managed care experts.

The class was held over the lunch hour once a week in small lecture halls on both campuses. In order to encourage discussions, meetings were later held at a roundtable instead of a lecture hall. Students worked in teams of 2-3 to develop presentations on managed care topics. Local managed care pharmacists and chapter diplomats were asked to participate in class via a teleconferencing system. The pharmacists provided feedback on presentation content and insight on each topic from real-world experience. The chapter diplomats received presentation materials by e-mail before each session to evaluate quality and content.

\section{Methods}

In order to determine the educational value of the course and further improve the course structure, a series of mandatory surveys were conducted throughout the fall and spring semesters of 2014-2015 and at the end of each semester. The surveys also provided students with the opportunity to peer evaluate each other, help colleagues develop presentation skills, and identify areas of improvement for the course as a whole.

After each presentation, enrolled students were required to complete an online survey consisting of 7 questions that evaluated the student presenters and provided constructive feedback. The completion of the survey also counted as attendance for the day. Five of the questions were based on a 5-point ranking system, in which students could indicate the quality of the presentation, how much they learned, and the level of engagement experienced. Two of the questions were open ended, and students could provide immediate feedback to their colleagues about their presentation skills. At the same time, students had the opportunity to indicate how the course could be further improved. At the end of each week, responses were shared with the presenters.

At the end of each semester, students completed a final 7-question survey to evaluate the effectiveness of the course, their comfort level regarding managed care topics, and future course improvement opportunities.

\section{Results}

Educational Value of the Managed Care Directed Study Course

The following data were obtained from a mandatory survey from course enrollees at the end of the 2015 spring semester to assess the educational value of the course. Based on the survey ( $n=17)$, the majority of students took the course based on their interest in managed care pharmacy; $12 \%$ of enrollees took the course because of word-of-mouth referrals from past students; and another $12 \%$ of enrollees took the course because they wanted to explore topics outside of the core curriculum. These data suggested that there was strong interest in managed care throughout the student body, and the course added value to students' education experience outside the core curriculum.

The survey also assessed student interest in pursuing managed care pharmacy as a career and found that $38 \%$ of the students were still unsure whether they would be pursuing a managed care career. The remaining $62 \%$ of the students had narrowed down their career options, and 44\% indicated that they were either "somewhat likely" or "most likely" to pursue a 
What did you like most about this class?

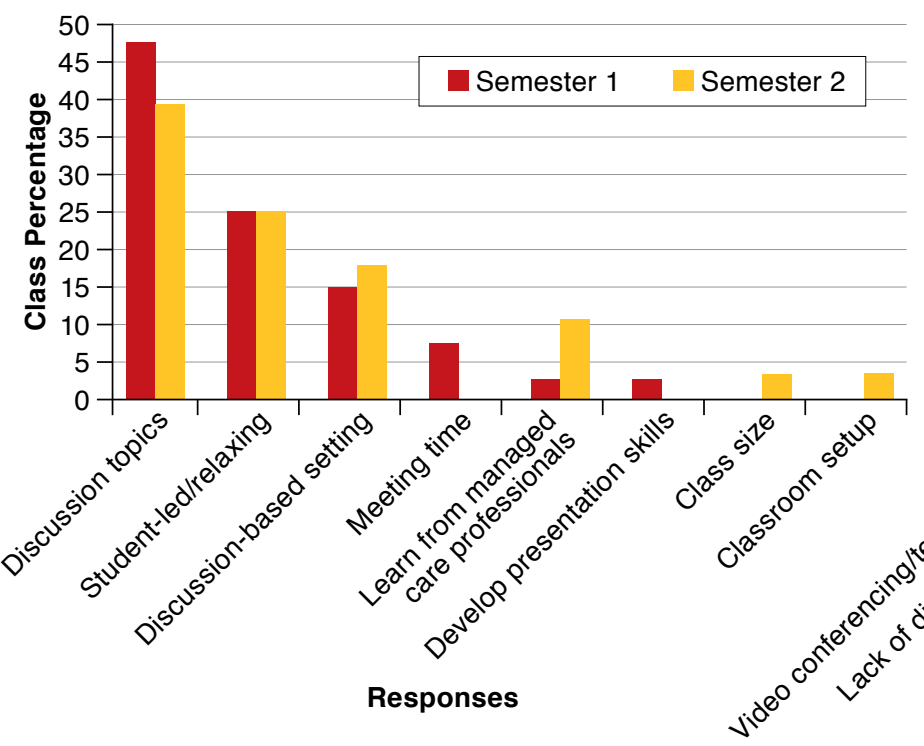

What did you like least about this class?



career in managed care pharmacy.

When asked about how comfortable students were discussing managed care topics with their peers, $50 \%$ of the students felt somewhat comfortable; 31\% felt very comfortable; and 19\% thought that they were about average. More important, none of the students answered "not comfortable" and "somewhat not comfortable," which indicated that the course successfully exposed students to a variety of topics in managed care pharmacy.

\section{Evaluation of Improvement over the 2 Semesters}

As previously mentioned, the course had 28 enrollees in the 2014 fall semester and 17 enrollees in the 2015 spring semester. Among the 28 enrollees in the fall semester, 8 students (28.5\%) continued enrollment in the spring semester.

In addition to enrollment numbers, other factors, such as meeting time, classroom setup, and classroom arrangement were also taken into account when evaluating survey responses by the students. During the fall semester, the class met regularly in a medium-sized classroom with a lecture-style setup (holding a maximum of 30 people), while in the spring semester, the class met in a small conference room with a round table setup (holding a maximum of 12 people). In addition, the class was held on a different day in the each semester because of time conflicts with other student organizations.

From the survey responses, summarized in Figure 1, it is evident that discussion topics, student-led/relaxing course structure, and discussion-based setting were among the most favorable elements of this course. More students also reported that they enjoyed having managed care professionals join the class meeting, the smaller class size, and meeting in a conference-style classroom. The unfavorable elements of the course are also shown in Figure 1, which indicates that the number of students who disliked the class size and lack of managed care professionals was reduced in the spring semester compared with the fall semester. The number of students who disliked the meeting time, lack of discussion, and participation was also reduced.

\section{Emerging New Challenges}

Despite the improvements to the course, there were some recurring issues and new challenges that needed to be addressed. As depicted in Figure 1, technical issues with teleconferencing, lack of participation in discussion, and lack of managed care professionals joining the meetings were consistent issues over the 2 semesters. New challenges, such as lack of assignments/ projects, lack of topic variety, and room size were also indicated. The issue regarding room size was mainly because of the larger number of enrollees from the Twin Cities campus, which exceeded the room capacity of the conference room.

In addition to the weekly surveys and end-of-semester surveys, another survey was conducted among the 8 students who enrolled in both semesters of the course for direct comparison purposes. As shown in Table 1, the majority of students found that the setup of the spring semester course encouraged more participation. Many of the students reported that there was more discussion and participation and that the smaller class 


\section{TABLE 1 Comparison of Fall and Spring} Semester Courses

\begin{tabular}{|c|c|c|}
\hline \multicolumn{3}{|c|}{ How engaged were you in the spring semester vs. the fall semester } \\
\hline Response $(n=8)$ & \multicolumn{2}{|c|}{ Percentage } \\
\hline A lot less engaged & \multicolumn{2}{|l|}{0} \\
\hline Slightly less engaged & \multicolumn{2}{|l|}{0} \\
\hline The same & 38 & $(n=3)$ \\
\hline Slightly more engaged & 25 & $(n=2)$ \\
\hline A lot more engaged & 38 & $(n=3)$ \\
\hline \multicolumn{3}{|c|}{ What did you like most about this class? } \\
\hline Response $(n=8)$ & \multicolumn{2}{|c|}{ Percentage } \\
\hline More discussion/participation & 38 & $(n=3)$ \\
\hline After-class survey & 13 & $(n=1)$ \\
\hline Smaller class size/classroom setup & 25 & $\mathrm{n}=2)$ \\
\hline Having 2 presenters rather than 3 & 13 & $(n=1)$ \\
\hline Less technical issues & 13 & $(n=1)$ \\
\hline \multicolumn{3}{|c|}{ What did you like least about this class? } \\
\hline Response $(n=8)$ & \multicolumn{2}{|c|}{ Percentage } \\
\hline Meeting time & 13 & $(n=1)$ \\
\hline Class setup/discussion format & 13 & $(n=1)$ \\
\hline Dual campus & 13 & $(n=1)$ \\
\hline None & 63 & $(n=5)$ \\
\hline \multicolumn{3}{|c|}{ How likely are you to pursue a managed care career in pharmacy? } \\
\hline Response $(\mathrm{n}=8)$ & \multicolumn{2}{|c|}{ Percentage } \\
\hline Not likely & 13 & $(n=1)$ \\
\hline Somewhat unlikely & 13 & $(\mathrm{n}=1)$ \\
\hline Maybe & 38 & $(n=3)$ \\
\hline Somewhat likely & 13 & $(n=1)$ \\
\hline Most likely & 25 & $(n=2)$ \\
\hline
\end{tabular}

size and change in classroom setup were beneficial to the learning environment. The amount of material learned was also evaluated, and students indicated that they learned more from the spring semester class compared with the class offered in the fall semester. About $20 \%$ of students who took the spring semester class indicated that they learned "a lot," which was an increase from $8 \%$ of the students who took the fall semester class.

As of July 2015, of the 6 students who completed the Managed Care Pharmacy Directed Study course and graduated from the University of Minnesota College of Pharmacy, 1 student was in the process of completing a fellowship, and 2 students were in the process of completing residencies in managed care. One student was working as a managed care pharmacist, and the remaining 2 students who participated in the survey were still involved in the course and were still members of the AMCP student chapter.

\section{Discussion}

The data collected from this study support the growing interest in managed care pharmacy, as well as the need for more managed care topics in the pharmacy school core curriculum. From the survey, $70 \%(n=12)$ of the students enrolled in the managed care directed study course because of their own interest in managed care pharmacy, and after completion of the elective, $28.5 \%$ students took the class again, which indicated that the course added value to students' educational experience outside the core curriculum. Students who took the course again were encouraged to present new topics and avoid repeating previous managed care topic presentations.

The roundtable format increased discussions, and often, students stayed after class to continue topic discussions. The smaller groups provided students with more opportunities to make the presentations their own and learn about a managed care topic most aligned with their interests. Even for students who were no longer interested in managed care pharmacy, they still benefited from the course, with more than $80 \%$ of the students indicating that they would be comfortable discussing managed care topics with other colleagues.

A student-designed and led managed care elective is a practical and effective strategy to incorporate more managed care content and practice experience into the pharmacy school core curriculum. Students who participated in the course indicated that they gained a lot from the experience. Participation in the course may have encouraged some students to pursue a managed care pharmacy career path.

In a constantly changing health care environment, it is now more important than ever for pharmacy students to graduate with a strong understanding of the rapidly evolving health care industry. We need strong leadership and creative solutions to solve some of the most complex challenges that face modern health care. This student-directed course was focused on introducing pharmacy students to, and engaging them in, discussion regarding current and emerging topics that will continue to define how health care will be practiced after graduation.

In order to offer this educational experience despite limited faculty time, student leaders with guidance from a faculty advisor created and led a managed care elective using a peer-led team teaching design framework. Peer-led team learning is an established educational model, which has its origins in science education and is built on the constructivist theoretical frameworks of cooperative and collaborative learning. ${ }^{3,4}$ This educational approach is an example of active learning that argues that meaningful learning is defined by student engagement with complex, authentic problems, as well as social interaction with peers and others. Intentionally using other learners as part of the educational design can be an effective approach. In addition to managing the workload of a course, peers are also a potential source of educational scaffolding, which is the support required for students to engage in authentic, complex tasks through demonstration, feedback, and other necessary resources to allow for successful completion. ${ }^{5,6}$

The use of expert peer-facilitated learning is not new, especially within health professional education. Ideally, with 
peer-to-peer teaching, peers learn from their experiences, while at the same time contribute to the learning of others. ${ }^{7}$ This learning strategy means that the entire instructional team is prepared to play the role of leader and teacher, and multiple opportunities existed to use this strategy throughout this course.

As health care continues to shift from the fee-for-service model to a more cost-effective outcomes-based payment model with the implementation of the Affordable Care Act, future pharmacists are uniquely positioned to take on new roles that affect patient care. Managed care combines clinical expertise, technology, business, and policy to meet many of the challenges facing health care today, and it is important for pharmacy students to better understand these concepts.

\section{Limitations}

This study has some limitations to consider. The foremost limitation is the small sample size from a single pharmacy institution. In addition, the setting of the course changed from a lecture format to a roundtable setup, which may have led to different responses to the course in the 2 semesters. However, the survey was answered anonymously, which allowed participants to be honest with their responses. Although the results from this small study may not apply to pharmacy schools with more emphasis on managed care, this study showed the need for more managed care topics within the University of Minnesota's pharmacy school core curriculum.

\section{Conclusions}

The peer-led team teaching discussion course on managed care pharmacy used in this study is a model for empowering students to educate themselves and discuss important and timely issues affecting modern health care. Data collected from students enrolled in the managed care elective indicated increased exposure and enhanced knowledge on the topics discussed. Data indicated value and support for the addition of peer-led courses to the University of Minnesota CoP's curriculum. Graduates who previously took the course have pursued managed care careers and confirmed the benefits of this course.

Further initiatives could be considered in order to better develop the course and help integrate managed care pharmacy into the core curriculum to ensure that all pharmacy students are exposed to this field.

\section{Authors}

SYHUI TANG, PharmD; JULIA SMITH, PharmD; WILSON LAU, PharmD; ISAAC TSE, PharmD, MBA; RYAN COTTEN, PharmD; and AMY PITTENGER, PharmD, MS, PhD, University of Minnesota College of Pharmacy, Minneapolis. CHRISTINE TAN, PharmD, EnvisionRx, El Dorado Hills, California.

AUTHOR CORRESPONDENCE: SyHui Tang, PharmD, University of Minnesota College of Pharmacy, 232 Life Science, 1110 Kirby Dr., Duluth, MN 55812. Tel.: 626.203.7811; E-mail: tangx436@d.umn.edu.

\section{DISCLOSURES}

No outside funding supported this study. The authors have nothing to disclose. Study concept and design were contributed by Tang, Smith, Tse, Tan, and Pittenger. Lau took the lead in data collection, along with Tang and Smith. Data interpretation was performed primarily by Lau, along with Tang, Smith, and Pittenger. The manuscript was written by all the authors and revised primarily by Tang, along with Smith, Lau, Pittenger, and Tan.

This research was presented as a poster at the Academy of Managed Care Pharmacy Nexus 2015; October 26-29, 2015; Orlando, Florida.

\section{ACKNOWLEDGMENTS}

The authors gratefully acknowledge support from course founder Jenny Wong; chapter advisors Randall Seifert, Dan Tomaszewski, and Abigail Stoddard; and AMCP diplomats Justine Meierhofer, John Mbagwu, and Lee Swenson.

\section{REFERENCES}

1. Pittenger AL, Starner CI, Thompson K, Gleason PP. Pharmacy students' views of managed care pharmacy and PBMs: should there be more exposure to managed care in the pharmacy curriculum? J Manag Care Pharm. 2010;16(5):346-54. Available at: http://www.jmcp.org/doi/10.18553/ jmcp.2010.16.5.346.

2. Johnson RC. Need for coursework in pharmacy curricula on managed care pharmacy. J Manag Care Pharm. 2010;16(6):427-27. Available at: http:// www.jmcp.org/doi/abs/10.18553/jmcp.2010.16.6.427.

3. Gosser DK, Cracolice MS, Kampmeier JA, Strozak VS, Varma-Nelson P. Peer-Led Team Learning: A Guidebook. Upper Saddle River, NJ: Prentice Hall; 2001.

4. Johnson DW, Johnson RT. Cooperation and the use of technology. In: Spector JM, Merill MD, van Merrienboer J, Driscoll MP, eds. Handbook of Research on Educational Communications and Technology. 3rd ed. New York: Lawrence Erlbaum; 2007:401-23.

5. Keller JM. First principles of motivation to learn and e3-learning. J Dist Educ. 2008:29(2):175-85.

6. Merrill, MD. First principles of instruction. Educ Technol Res Dev. 2002;50(3):43-59. Available at: http://www.springerlink.com/content/ v654r53735507576/fulltext.pdf. Accessed May 5, 2017.

7. Boud, D. Introduction: making the move to peer learning. In: Boud D, Cohen R, Sampson J, eds. Peer Learning in Higher Education. Sterling, VA: Stylus Publishing; 2001:1-20. 